\title{
Thrice-Weekly Nocturnal In-Centre Haemodiafiltration: A 2-Year Experience
}

\author{
Vishal Dey Mario Hair Beng So Elaine M. Spalding \\ John Stevenson Lynch Renal Unit, Crosshouse Hospital, Kilmarnock, UK
}

Key Words

Dialysis adequacy · Haemodialysis · Phosphate

\begin{abstract}
Background: Adequate control of plasma phosphate without phosphate binders is difficult to achieve on a thrice-weekly haemodialysis schedule. The use of quotidian nocturnal dialysis is effective but not practical in the in-centre setting. This quality improvement project was set up as an exercise allowing the evaluation of small-solute clearance by combining convection with extended-hour dialysis in a thrice-weekly hospital setting. Methods: A single-centred, prospective analysis of patients' electronic records was performed from August 2012 to July 2014. The duration of haemodiafiltration was increased from a median of 4.5 to $8 \mathrm{~h}$. Dialysis adequa$c y$, biochemical parameters and medications were reviewed on a monthly basis. A reduction in plasma phosphate was anticipated, so all phosphate binders were stopped. Results: Since inception, 14 patients have participated with over 2,000 sessions of dialysis. The pre-dialysis phosphate level fell from a mean of $1.52 \pm 0.4$ to $1.06 \pm 0.1 \mathrm{mmol} / \mathrm{l}(p<0.05)$. The average binder intake of $3.26 \pm 2.6$ tablets was eliminated. A normal plasma phosphate range has been maintained with increased dietary phosphate intake and no requirement for intradialytic phosphate supplementation. Conclusion: Phosphate control can be achieved without the need for binders or supplementation on a thrice-weekly in-centre haemodiafiltration program.
\end{abstract}

\section{Introduction}

Patients undergoing conventional dialysis 3 times at 4-hour sessions per week exhibit an excess mortality rate 4 times higher than that of the general population for patients under 30 years, and 6 times that of the general population for patients above 65 years [1]. This increased 
mortality has been attributed to a low dialysis dose [2], but two large randomised controlled trials have failed to show any survival benefit for patients receiving a larger dialysis dose $[3,4]$.

In an effort to improve outcomes, multiple treatment schedules have been utilised. On-line haemodiafiltration (OL-HDF), which combines diffusion and convection, has grown in popularity over the last 20 years. This provides enhanced clearance of toxins $[5,6]$, increased haemodynamic stability [7] and better quality of life [8]. The use of more frequent dialysis has also been shown to be beneficial $[9,10]$. The advantages in bone mineral profile $[11,12]$, blood pressure (BP) control [13], patient experience and improved mortality [14] in programs with extended-hour dialysis have been well demonstrated. This is often not an acceptable alternative for patients, and few of the studies of extended-hour dialysis are based in a centre, as the majority of patients in these studies undertake nocturnal dialysis at home. The use of convective therapy in combination with extended-hour dialysis has been shown to be beneficial [15] but is not frequently described.

We have established a program of thrice-weekly 7- to 8-hour nocturnal OL-HDF in our centre in the belief that this will improve quality of dialysis by combining convection with extended-hour treatment. This seemed an excellent compromise for patients who could not have home dialysis but wanted to benefit from having extended hours. The frequency was kept at thrice weekly due to patient preference. The program initially started with 10 patients, and over a 2-year period our patients have had over 2,000 sessions of OL-HDF.

\section{Methods}

Data were collected prospectively from patients' electronic records over a 2-year period. Patients were self-selected with no stipulated exclusion criteria apart from patients needing to have their own transport due to the timing of commencement and cessation of treatment. Only 10 patients initially came forward.

\section{Patient Characteristics}

During the study period, 14 patients (13 male and 1 female) started nocturnal OL-HDF. The mean age was $45.2 \pm 13.1$ years (range 23.8-66.2), and renal replacement treatment vintage was $42.34 \pm 40.62$ months (range 6.61-116.94). All patients were on regular OL-HDF for at least 6 months [mean $30.93 \pm 27.68$ (range 6.67-93.44)] prior to conversion to the nocturnal regime.

The cause of end-stage renal disease was pyelonephritis/interstitial nephritis, Alport's disease, haemolytic uremic syndrome, reflux nephropathy, membranous nephropathy and renovascular disease ( 1 patient each); adult polycystic kidney disease, IgA nephropathy, rapid progressive glomerulonephritis and unknown causes (2 patients each). All patients except one had a native arteriovenous fistula. Drop-out reasons prior to 12 months were planned change in modality ( 1 patient), transplantation (3 patients) or lifestyle choice (1 patient).

Ethical approval was not sought, as this study was a part of quality improvements to services.

\section{Nocturnal Treatment Regime}

Patients on standard 4- to 5-hour thrice-weekly OL-HDF were switched to 7- to 8-hour thrice-weekly nocturnal OL-HDF. Patients were dialysed using a Fresenius 5008 machine and a Gambro Polyflux dialyser, without reuse. The blood flow (Qb) was reduced to $200 \mathrm{ml} / \mathrm{min}$, and dialysate flow (Qd) was reduced to $300 \mathrm{ml} / \mathrm{min}$. All patients continued on post-dilution 
OL-HDF with a dialysate calcium concentration of $1.75 \mathrm{mmol} / \mathrm{l}$ and potassium adjusted according to pre-dialysis levels. The dialysate bicarbonate concentration was reduced to prevent the development of alkalosis, and anticoagulation was increased by $50 \%$.

\section{Review of Biochemical and Clinical Parameters}

A monthly review of dialysis adequacy, electrolytes and haemoglobin ( $\mathrm{Hb}$ ) measurements was carried out. The baseline biochemical parameters were calculated from the averages of the last 3 months during standard thrice-weekly 4- to 5-hour OL-HDF. Routine samples (before and after dialysis) were collected on the first weekday of the short intradialytic gap of the month. Small-solute clearance was assessed using a standard Kt/V equation (Std Kt/V) [16] with mineral bone disease monitored by plasma phosphate and calcium levels. A reduction in plasma phosphate was expected, so all phosphate binders were stopped. All patients were assessed by a qualified renal dietician and advised to relax their phosphate restriction.

Samples for ferritin and vitamin $\mathrm{B}_{12}$ were analysed every 3 months and for parathyroid hormone (PTH) and $\beta-2$ microglobulin every 6 months. Doses of intravenous iron, erythropoietin (darbepoetin- $\alpha$ ) and BP medication use were recorded. Changes in medication were at the discretion of the responsible physician.

Average readings of clinical parameters, i.e. BP, weight and hydration, were assessed using a multi-channel bioimpedance Fresenius ${ }^{\circledR}$ body mass composition monitor and analysed with Fluid Management Tool software version 3.3.0.1637 on a quarterly basis.

\section{Statistical Analysis}

Data were recorded prospectively for a period of 24 months and included in the analysis where 12 months or more of data were available. These data were analysed using SPSS software package version 17. A repeated measure of analysis of variance was performed with respect to baseline. Each patient served as his/her own control. As the sample size was small, non-parametric statistics were used to compare readings at 24 months with baseline using the Wilcoxon signed-rank test. A value of $\mathrm{p}<0.05$ was considered statistically significant.

\section{Results}

\section{Bone Profile}

The pre-dialysis phosphate level fell from a mean of $1.52 \pm 0.41$ to $1.21 \pm 0.2,1.26 \pm 0.45$, $1.28 \pm 0.32$ and $1.06 \pm 0.13 \mathrm{mmol} / \mathrm{l}$ at $3,6,9$ and 24 months, respectively $(\mathrm{p}<0.05$ at 24 months; table 1; fig. 1). The use of binders dropped from an average of $3.26 \pm 2.63$ tablets to zero ( $p<0.05$; table 1 ; fig. 1 ). None of the patients have required recommencement of a phosphate binder or supplementation during dialysis due to low phosphate levels.

Calcium levels were non-significantly raised at 24 months, which theoretically could lead to a positive calcium balance. PTH, however, fell from $39.24 \pm 31.4 \mathrm{pmol} / \mathrm{l}$ at baseline to 23.97 \pm 27.1 and $26.13 \pm 12.6 \mathrm{pmol} / \mathrm{l}$ at 12 and 24 months, respectively $(\mathrm{p}<0.05$; data not shown). This failed to reach significance when the patient on cinacalcet was excluded $(p=0.08$ at 6 months and $p=0.07$ at 12 and 24 months; table 2 ). None of the patients has required a parathyroidectomy.

\section{Small-Solute Clearance}

Std Kt/V increased from $2.37 \pm 0.21$ (range 1.93-2.65) to $2.68 \pm 0.16$ (range 2.52-2.92) at 24 months, with $\mathrm{p}<0.05$ at 3, 6, 9 and 24 months compared to baseline (table 1; fig. 2). 


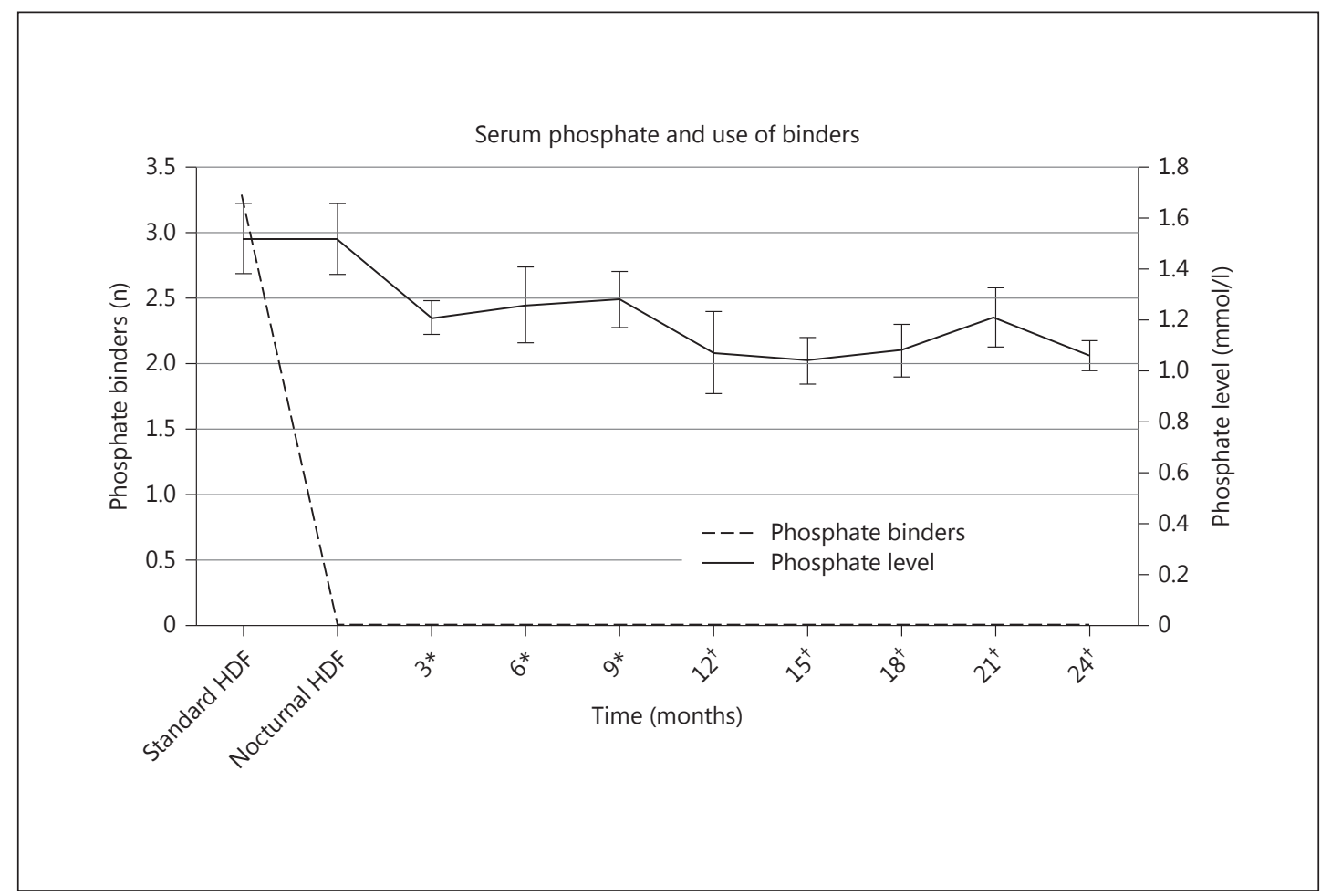

Fig. 1. Significant reduction in the use of phosphate binders ( $p<0.05$ at 3, 6, 9 and 24 months) and phosphate levels ( $p<0.05$ at 24 months) on conversion from standard 4-hour HDF to nocturnal 8-hour HDF. Means \pm standard deviations are given. ${ }^{*} n=9,{ }^{\dagger} n=5$, where $n$ is the number of patients.

Table 1. Change from thrice-weekly OL-HDF (4-5 h) to thrice-weekly nocturnal HDF (7-8 h)

\begin{tabular}{|c|c|c|c|c|c|}
\hline & Baseline & $\begin{array}{l}3 \text { months } \\
(n=9)\end{array}$ & $\begin{array}{l}6 \text { months } \\
(\mathrm{n}=9)\end{array}$ & $\begin{array}{l}9 \text { months } \\
(n=9)\end{array}$ & $\begin{array}{l}24 \text { months } \\
(n=5)\end{array}$ \\
\hline Time, min & $277.22 \pm 25.80$ & $474.26 \pm 9.58^{\mathrm{a}}$ & $472.52 \pm 7.92^{\mathrm{a}}$ & $476.85 \pm 5.99^{a}$ & $466.60 \pm 13.68^{c}$ \\
\hline Volume, l & $22.54 \pm 3.91$ & $27.53 \pm 3.19^{b}$ & $27.25 \pm 3.34^{\mathrm{b}}$ & $28.26 \pm 3.79^{a}$ & $28.85 \pm 2.22^{\mathrm{c}}$ \\
\hline URR & $0.76 \pm 0.08$ & $0.84 \pm 0.05^{\mathrm{a}}$ & $0.83 \pm 0.06^{\mathrm{a}}$ & $0.83 \pm 0.05^{\mathrm{b}}$ & $0.85 \pm 0.04^{\mathrm{c}}$ \\
\hline Std Kt/V & $2.37 \pm 0.21$ & $2.68 \pm 0.18^{\mathrm{a}}$ & $2.62 \pm 0.25^{b}$ & $2.61 \pm 0.19^{b}$ & $2.68 \pm 0.16^{c}$ \\
\hline Corr. Ca, mmol/l & $2.34 \pm 0.22$ & $2.37 \pm 0.17$ & $2.41 \pm 0.15$ & $2.39 \pm 0.14$ & $2.48 \pm 0.19$ \\
\hline $\mathrm{PO}_{4}, \mathrm{mmol} / \mathrm{l}$ & $1.52 \pm 0.41$ & $1.21 \pm 0.20$ & $1.26 \pm 0.45$ & $1.28 \pm 0.32$ & $1.06 \pm 0.13^{c}$ \\
\hline $\mathrm{PO}_{4}$ binders & $3.26 \pm 2.63$ & $0.00 \pm 0.00^{\mathrm{a}}$ & $0.00 \pm 0.00^{\mathrm{a}}$ & $0.00 \pm 0.00^{\mathrm{a}}$ & $0.00 \pm 0.00^{\mathrm{c}}$ \\
\hline $\mathrm{Hb}, \mathrm{g} / \mathrm{dl}$ & $11.58 \pm 1.35$ & $11.55 \pm 0.97$ & $11.19 \pm 1.58$ & $12.10 \pm 0.72$ & $11.96 \pm 0.47$ \\
\hline Ferritin, $\mu \mathrm{g} / \mathrm{l}$ & $492.85 \pm 295.04$ & $463.17 \pm 305.99$ & $423.00 \pm 247.00$ & $342.33 \pm 152.44$ & $321.40 \pm 117.27$ \\
\hline EPO, weekly dose & $21.85 \pm 21.61$ & $12.96 \pm 16.11$ & $18.52 \pm 16.92$ & $15.74 \pm 13.67$ & $15.00 \pm 8.66$ \\
\hline Iron dose, mg/week & $50.93 \pm 28.40$ & $29.63 \pm 32.30^{\mathrm{b}}$ & $26.85 \pm 23.12^{b}$ & $22.22 \pm 23.20^{\mathrm{b}}$ & $45.00 \pm 32.60$ \\
\hline Vitamin $\mathrm{B}_{12}, \mathrm{ng} / \mathrm{l}$ & $440.07 \pm 108.51$ & $480.56 \pm 138.48$ & $520 \pm 141.55$ & $429.67 \pm 128.71$ & $331.80 \pm 37.35$ \\
\hline Overhydration, l & $1.53 \pm 2.96$ & $1.31 \pm 1.48$ & $1.48 \pm 1.21$ & $1.08 \pm 1.21$ & $1.81 \pm 2.44$ \\
\hline Systolic BP, mm Hg & $146.63 \pm 21.77$ & $139.52 \pm 26.68$ & $137.26 \pm 25.18$ & $140.30 \pm 30.22$ & $137.47 \pm 17.30$ \\
\hline Diastolic BP, mm Hg & $75.04 \pm 12.84$ & $70.20 \pm 15.03$ & $67.07 \pm 20.09$ & $70.94 \pm 17.16$ & $69.40 \pm 13.84$ \\
\hline BP medications & $1.31 \pm 1.04$ & $0.70 \pm 1.31^{\mathrm{b}}$ & $0.56 \pm 1.33^{\mathrm{b}}$ & $0.67 \pm 1.32^{\mathrm{b}}$ & $0.60 \pm 0.89^{c}$ \\
\hline
\end{tabular}

Values are means \pm standard deviations. Corr. $\mathrm{Ca}=$ Corrected calcium; EPO = erythropoietin; $\mathrm{PO}_{4}=$ phosphate; URR = urea reduction ratio.

${ }^{\mathrm{a}} \mathrm{p}<0.01$, with respect to baseline; repeated-measures analysis of variance (ANOVA). ${ }^{\mathrm{b}} \mathrm{p}<0.05$, with respect to baseline; ANOVA. ${ }^{c} \mathrm{p}<0.05$, Wilcoxon signed-rank test. 
Dey et al.: Thrice-Weekly Nocturnal In-Centre Haemodiafiltration: A 2-Year Experience

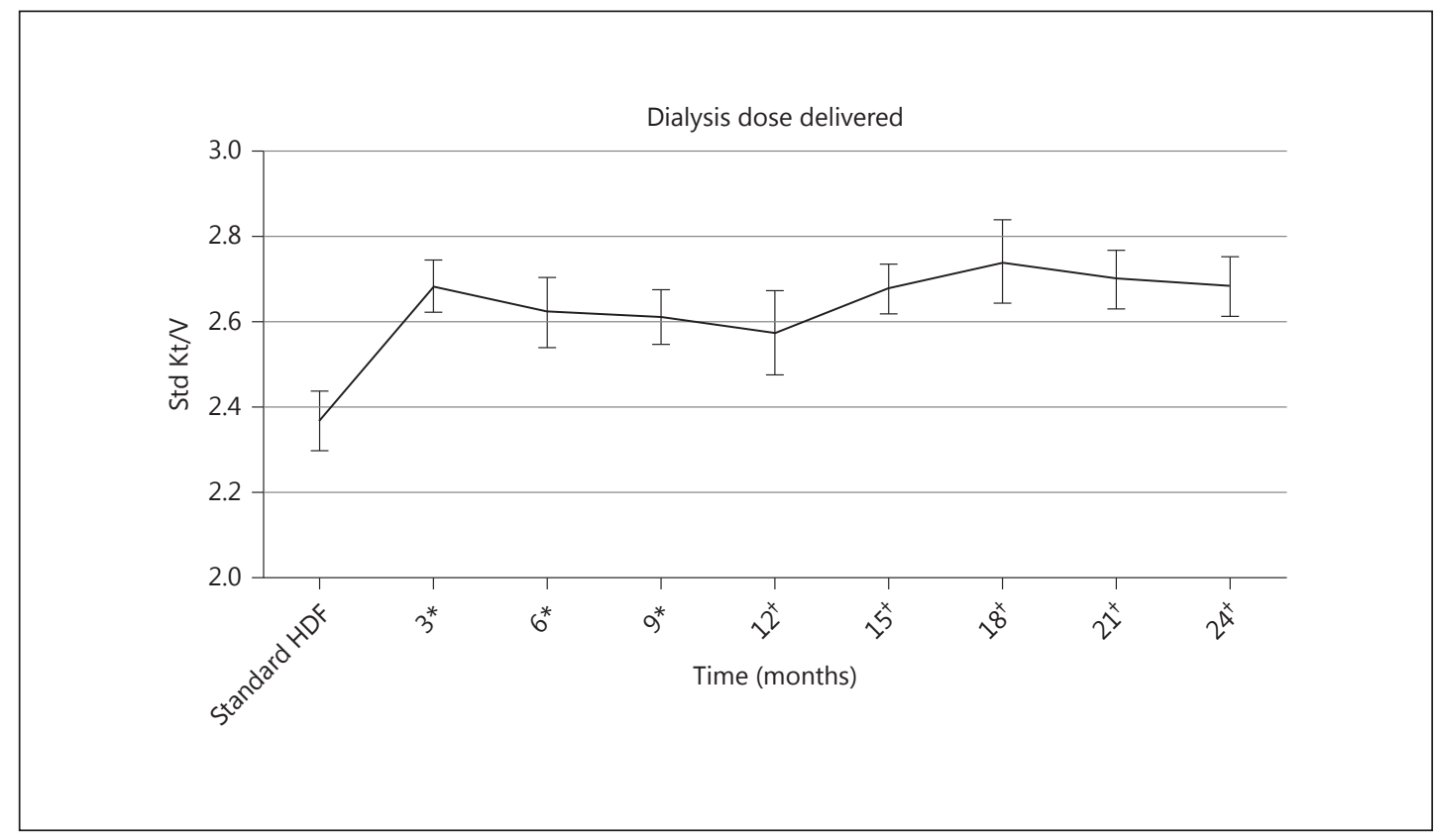

Fig. 2. Significant improvement in the dialysis dose delivered (Std Kt/V) on conversion from standard 4-hour HDF to nocturnal 8-hour HDF at 3, 6, 9, 12 and 24 months. Means \pm standard deviations are given. ${ }^{*} \mathrm{n}=9$, ${ }^{\dagger} \mathrm{n}=5$, where $\mathrm{n}$ is the number of patients.

Table 2. Changes in $\beta$-2 microglobulin and PTH levels on changing from thrice-weekly OL-HDF (4-5 h) to thrice-weekly nocturnal OL-HDF (7-8 h)

\begin{tabular}{lllll}
\hline & Baseline & 6 months & 12 months & 24 months \\
\hline$\beta 2 \mathrm{~m}, \mathrm{mg} / \mathrm{dl}$ & $23.34 \pm 9.19$ & $\begin{array}{l}20.88 \pm 5.99 \\
(\mathrm{n}=9)\end{array}$ & $\begin{array}{l}20.99 \pm 5.21 \\
(\mathrm{n}=9)\end{array}$ & $\begin{array}{l}24.09 \pm 3.13 \\
(\mathrm{n}=5)\end{array}$ \\
\hline PTH, pmol/l & $30.52 \pm 14.55$ & $\begin{array}{l}21.93 \pm 22.53 \\
(\mathrm{n}=7)\end{array}$ & $\begin{array}{l}15.45 \pm 11.84 \\
(\mathrm{n}=7)\end{array}$ & $\begin{array}{l}20.84 \pm 4.82 \\
(\mathrm{n}=4)\end{array}$
\end{tabular}

Values are means \pm standard deviations. PTH data of the patient on cinacalcet were omitted. No significant reduction was observed over time, although changes are almost significant ( $p=0.08$ at 6 months, $p=0.07$ at 12 and 24 months). There was no significant change for $\beta-2$ microglobulin.

$\beta 2 \mathrm{~m}=\beta-2$ microglobulin.

\section{Middle-Molecule Clearance}

$\beta-2$ microglobulin levels showed no significant change. Baseline levels were $23.34 \pm 9.19$ $\mathrm{mg} / \mathrm{l}$ and levels at 6,12 and 24 months were $20.88 \pm 5.99,20.99 \pm 5.21$ and $24.09 \pm 3.13 \mathrm{mg} / \mathrm{l}$, respectively (table 2 ).

\section{Filtration Volume}

The OL-HDF substitution volume increased from $22.53 \pm 3.91$ litres per session to 27.53 \pm 3.19 litres at 3 months and $27.25 \pm 3.34,28.26 \pm 3.79$ and $28.85 \pm 2.22$ litres at 6,9 and 24 months, respectively ( $\mathrm{p}<0.05$ at $3,6,9$ and 24 months). 


\section{BP, Fluid Status and Antihypertensive Medications}

$B P$ reduction and changes in overhydration status did not reach statistical significance, but the use of antihypertensive medications decreased from $1.31 \pm 1.04$ to $0.6 \pm 0.89$ tablets at 24 months $(\mathrm{p}<0.05)$.

\section{Haematological Parameters and Erythropoietin Dose}

Intravenous iron use showed a significant decrease from baseline $50.93 \pm 28.4$ to 29.63 $\pm 32.3,26.85 \pm 23.12$ and $22.22 \pm 23.2 \mathrm{mg} /$ week at 3,6 and 9 months, respectively, but not at 24 months ( $45 \pm 32.6 \mathrm{mg} /$ week). Erythropoietin use decreased but did not reach statistical significance. Hb levels did not change significantly.

\section{Discussion}

Thrice-weekly extended-hour nocturnal OL-HDF seems to be an excellent alternative to current modalities of dialysis. It achieves targets for small-solute clearance and mineral bone disease with elimination of phosphate binders and no dietary phosphate restrictions. It has been accepted and well tolerated by patients.

The unique finding of this study is the complete elimination of phosphate binders without the requirement for intradialytic phosphate supplementation. Phosphate control with dialysis alone was first described in 1998 where patients were converted from conventional thrice-weekly dialysis to dialysis 6 nights weekly. Normal phosphate levels were achieved at 5 months despite a $50 \%$ increase in phosphate intake in diet. The blood flow rate was $300-350 \mathrm{ml} / \mathrm{min}$ and the dialysate flow rate $500 \mathrm{ml} / \mathrm{min}$ [11]. A recent paper by Maduell et al. [15] to evaluate the beneficial effects of alternate-day nocturnal OL-HDF reported a reduction in serum phosphorus from $4.93 \pm 1.5 \mathrm{mg} / \mathrm{dl}(1.59 \pm 0.48 \mathrm{mmol} / \mathrm{l})$ to $3.74 \pm 1 \mathrm{mg} / \mathrm{dl}(1.20 \pm 0.32 \mathrm{mmol} / \mathrm{l})$ at 12 months. Phosphate binders were reduced, but not eliminated, and intradialytic supplementation was needed in $55 \%$ patients. Blood flows were $400 \mathrm{ml} / \mathrm{min}$ and dialysate flows were $500 \mathrm{ml} / \mathrm{min}$. The Australian experience of converting patients from a conventional regime to home nocturnal 6- to 9-hour sessions 3.5-4 times weekly resulted in a significant reduction in phosphate levels, again with a reduction in phosphate binder consumption but with $22.7 \%$ patients needing supplementation. Blood flow was 200-250 ml/min with a dialysate flow of $500 \mathrm{ml} / \mathrm{min}$ [17]. A recent study by a Dutch group comparing conventional [4-hour haemodialysis (HD) and HDF] and extended (8-hour HD and HDF) dialysis reported 'treatment time' as a major determinant of small-molecule clearance and haemodynamic stability. The total solute removal (urea, uric acid, creatinine and phosphate) was higher in the longer-duration treatments, with no difference noted in the treatment modalities (HD vs. HDF). Acute effects were only studied in this randomised cross-over trial. Blood flow was $300 \mathrm{ml} / \mathrm{min}$ and dialysate flow $600 \mathrm{ml} /$ min in all study sessions [18]. The improvement in small-solute clearance is consistent with other published reports $[15,19]$. The normal serum phosphate without the need for supplementation, previously not reported, could either be due to the lower dialysate and blood flows employed or to the reduced frequency of HDF 3 times per week. We, however, could not demonstrate a reduction in middle-molecule levels ( $\beta-2$ microglobulin). This may be due to the high substitution volumes utilised at baseline in these patients, but it suggests that dialysis duration per se is a less important factor in achieving higher $\beta$ - 2 microglobulin clearance.

Other biochemical parameters such as $\mathrm{Hb}$ did not change, though there was a trend towards a reduction in iron and erythropoietin doses. This lowering in erythropoietin doses might have been achieved if iron doses had not been decreased. 
Charra et al. [13] in France have reported one of the lowest mortality and morbidity statistics in dialysis patients. Absence of cardiovascular complications and good BP was achieved with maintenance of dry weight, a low-salt diet and no antihypertensive drugs. Despite following a similar regime, our BP lowering did not reach statistical significance. There was a reduction in antihypertensive medications during the study without change in BP, which may suggest overall better BP control. Overhydration (table 1) from a high salt intake contributing to extracellular volume expansion may explain why a significant reduction in BP was not demonstrated.

We noted a significantly higher substitution volume following transfer to the nocturnal program. Theoretically, this may confer a survival advantage in the longer term, as implied by a post hoc sub-analysis of data from two recent randomised controlled trials which showed a lower mortality rate with higher substitution volumes of $>17.4$ and $>21.95$ litres per session $[3,4]$.

\section{Limitations}

Our study has limitations due to the small patient numbers and being observational in nature. All patients were self-selected, thus, undoubtedly, more motivated and may have less co-morbidities than conventional dialysis patients. Post-dialysis phosphate monitoring was not conducted. No food charts or 24-hour urine collections were formally recorded to assess increased dietary intake of phosphate, but it is difficult to imagine that patients advised to follow a relaxed diet would continue to adhere to phosphate restriction. Residual renal function was not measured, but as each patient acted as their own control, it is unlikely that this would contribute to the benefits seen. Finally, we do not have a parallel comparator group comparing HD and HDF.

\section{Conclusion}

Nocturnal thrice-weekly in-centre OL-HDF is a practical alternative and is superior to conventional OL-HDF in terms of small-solute clearance and control of phosphate and allows a reduction in medication. It has the potential to improve outcomes, but this as yet remains unproven. It has been well tolerated by this patient group and should be considered as a treatment alternative for patients receiving hospital-based HD therapy.

\section{Acknowledgements}

This paper was presented as an abstract at the ERA-EDTA 50th Congress in Istanbul, 2013.

\section{Disclosure Statement}

The authors have no conflicts of interest to declare. 


\section{References}

1 Bayliss G, Danziger J: Nocturnal versus conventional haemodialysis: some current issues. Nephrol Dial Transplant 2009;24:3612-3617.

2 Hull AR: The 1989 morbidity and mortality meeting: how far have we come? Am J Kidney Dis 1998;32:S6-S8.

3 Grooteman MP, van den Dorpel MA, Bots ML, Penne EL, van der Weerd NC, Mazairac AH, den Hoedt CH, van der Tweel I, Levesque R, Nube MJ, ter Wee PM, Blankestijn PJ; CONTRAST Investigators: Effect of online hemodiafiltration on all-cause mortality and cardiovascular outcomes. J Am Soc Nephrol 2012;23:1087-1096.

4 Ok E, Asci G, Toz H, Ok ES, Kircelli F, Yilmaz M, Hur E, Demirci MS, Demirci C, Duman S, Basci A, Adam SM, Isik IO, Zengin M, Suleymanlar G, Yilmaz ME, Ozkahya M; Turkish Online Haemodiafiltration Study: Mortality and cardiovascular events in online haemodiafiltration (OL-HDF) compared with high-flux dialysis: results from the Turkish OL-HDF Study. Nephrol Dial Transplant 2013;28:192-202.

5 Pedrini LA, De Cristofaro V, Comelli M, Casino FG, Prencipe M, Baroni A, Campolo G, Manzoni C, Coli L, Ruggiero P, Acquistapace I, Auriemma L: Long-term effects of high-efficiency on-line haemodiafiltration on uraemic toxicity. A multicentre prospective randomized study. Nephrol Dial Transplant 2011;26:2617-2624.

6 Davenport A, Gardner C, Delaney M; Pan Thames Renal Audit Group: The effect of dialysis modality on phosphate control: haemodialysis compared to haemodiafiltration. The Pan Thames Renal Audit. Nephrol Dial Transplant 2010;25:897-901.

7 Locatelli F, Altieri P, Andrulli S, Bolasco P, Sau G, Pedrini LA, Basile C, David S, Feriani M, Montagna G, Di Iorio BR, Memoli B, Cravero R, Battaglia G, Zoccali C: Hemofiltration and hemodiafiltration reduce intradialytic hypotension in ESRD. J Am Soc Nephrol 2010;21:1798-1807.

8 Canaud B, Bowry SK: Emerging clinical evidence on online hemodiafiltration: does volume of ultrafiltration matter? Blood Purif 2013;35:55-62.

9 Chan CT, Greene T, Chertow GM, Kliger AS, Stokes JB, Beck GJ, Daugirdas JT, Kotanko P, Larive B, Levin NW, Mehta RL, Rocco M, Sanz J, Yang PC, Rajagopalan S; Frequent Hemodialysis Network Trial Group: Effects of frequent hemodialysis on ventricular volumes and left ventricular remodeling. Clin J Am Soc Nephrol 2013;8: 2106-2116.

10 Yuen D, Richardson RM, Chan CT: Improvements in phosphate control with short daily in-center hemodialysis. Clin Nephrol 2005;64:364-370.

11 Mucsi I, Hercz G, Uldall R, Ouwendyk M, Francoeur R, Pierratos A: Control of serum phosphate without any phosphate binders in patients treated with nocturnal hemodialysis. Kidney Int 1998;53:1399-1404.

12 Tang HL, Wong JH, Poon CK, Tang CM, Chu KH, Lee W, Fung SK, Chau KF, Li CS, Tong KL: One year experience of nocturnal home haemodialysis with an alternate night schedule in Hong Kong. Nephrology (Carlton) 2011; 16:57-62.

13 Charra B, Calemard E, Cuche M, Laurent G: Control of hypertension and prolonged survival on maintenance hemodialysis. Nephron 1983;33:96-99.

14 Laurent G, Charra B: The results of an $8 \mathrm{~h}$ thrice weekly haemodialysis schedule. Nephrol Dial Transplant 1998;13(suppl 6):125-131.

15 Maduell F, Arias M, Duran CE, Vera M, Fontsere N, Azqueta M, Rico N, Perez N, Sentis A, Elena M, Rodriguez N, Arcal C, Bergada E, Cases A, Bedini JL, Campistol JM: Nocturnal, every-other-day, online haemodiafiltration: an effective therapeutic alternative. Nephrol Dial Transplant 2012;27:1619-1631.

16 Gotch FA, Sargent JA: A mechanistic analysis of the National Cooperative Dialysis Study (NCDS). Kidney Int 1985;28:526-534.

17 Van Eps CL, Jeffries JK, Anderson JA, Bergin PT, Johnson DW, Campbell SB, Carpenter SM, Isbel NM, Mudge DW, Hawley CM: Mineral metabolism, bone histomorphometry and vascular calcification in alternate night nocturnal haemodialysis. Nephrology (Carlton) 2007;12:224-233.

18 Cornelis T, van der Sande FM, Eloot S, Cardinaels E, Bekers O, Damoiseaux J, Leunissen KM, Kooman JP: Acute hemodynamic response and uremic toxin removal in conventional and extended hemodialysis and hemodiafiltration: a randomized crossover study. Am J Kidney Dis 2014;64:247-256.

19 Powell JR, Oluwaseun O, Woo YM, Padmanabhan N, Narasinghan E, Latta C, Tortolano J, Jardine AG, Geddes CC: Ten years experience of in-center thrice weekly long overnight hemodialysis. Clin J Am Soc Nephrol 2009; 4:1097-1101. 